\title{
Effect of Thiadiazine Derivatives on Intracellular Amastigotes of Leishmania amazonensis
}

\author{
Lianet Monzote Fidalgo/ ${ }^{+}$, Ana Margarita Montalvo Álvarez, Lisset Fonseca Geigel, \\ Rolando Pérez Pineiro*, Margarita Suárez Navarro*, Hortensia Rodríguez Cabrera*
}

Departamento de Parasitología, Instituto de Medicina Tropical "Pedro Kourí”, Apartado Postal No. 601, Marianao 13, Ciudad de la Habana, Cuba *Laboratorio de Síntesis Orgánica, Facultad de Química, Universidad de la Habana, Cuba

Current therapy for leishmaniasis is not satisfactory. We describe the in vitro antiproliferative effects of new thiadiazine derivatives against Leishmania amazonensis. The compounds were found to be active against the amastigote form of the parasite, inhibiting parasite growing, from 10 to $89 \%$, at a concentration of $100 \mathrm{ng} / \mathrm{ml}$. This activity suggests that thiadiazine derivatives could be considered as potential antileishmanial compounds.

Key words: Leishmania - thiadiazine - amastigotes

The recommended drugs for the treatment of leishmaniasis are pentavalent antimonials, but amphotericin B, lipid formulations of amphotericin B, aminosidine, and pentamidine are also available (Plock et al. 2001). All these drugs have limitations related to the need for parenteral administration and long courses of treatment, toxicity and/ or high cost (Escobar et al. 2001). Several new antileishmanial compounds are under development, but a drug with the capacity to completely cure this infection has yet to be discovered (Delorenzi et al. 2001). Furthermore, at a time when the efficacy of currently available drugs is declining, there is an urgent need to search for novel antiprotozoal agents (Mikus et al. 2000).

The disubstituted-tetrahydro-2H-1,3,5-thiadiazine-2thione derivatives were previously reported to have activity against Trypanosoma cruzi (Ochoa et al. 1999). Taking into account this result, we decided to test ten of these thiadiazine derivatives against amastigotes of Leishmania amazonensis, which also belong to the order Kinetoplastida.

The compounds tested were synthesised as previously described (Ochoa et al. 1999). Equimolar quantities of the amine, $20 \% \mathrm{KOH}$ and carbon disulphide in $25 \mathrm{ml}$ of water were stirred for $4 \mathrm{~h}$. Two equivalents of $37 \%$ formaldehyde were then added and stirring continued for $1 \mathrm{~h}$. The mixture was filtered, added to a suspension of the corresponding aminoacid $(\mathrm{pH} 7.8-8)$ and stirred again for $2 \mathrm{~h}$. The solution was cooled, acidified with $\mathrm{HCl}(15 \%)$, filtered, washed with cold water and dried. Using ${ }^{1} \mathrm{H}$ - and ${ }^{13} \mathrm{C}-\mathrm{NMR}$ method the identities and purities of the compounds were verified. The basic structure and the substitutions of the compounds are shown in Fig. 1.

${ }^{+}$Corresponding author. Fax: +53-7-204.6051. E-mail: monzote@ipk.sld.cu

Received 4 July 2003

Accepted 15 March 2003

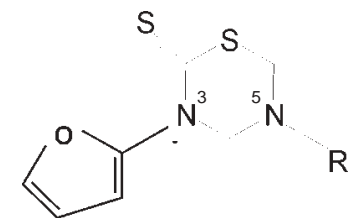

T1A: $\mathrm{R}=-\mathrm{Ch}_{2}-\mathrm{COOH}$

T1B: $\mathrm{R}=-\left(\mathrm{CH}_{2}\right)_{2}-\mathrm{COOH}$

T1C: $\mathrm{R}=-\left(\mathrm{CH}_{2}\right)_{5}-\mathrm{COOH}$

T1D: $\mathrm{R}=-\mathrm{CH}\left(\mathrm{CH}_{3}\right)-\mathrm{COOH}$

$\mathrm{T} 1 \mathrm{H}: \mathrm{R}=-\mathrm{CH}\left(\mathrm{CH}_{2}-\mathrm{Ph}\right)-\mathrm{COOH}$
T1I: $\mathrm{R}=-\mathrm{CH}\left(\mathrm{CH}_{2}-\mathrm{CONH}_{2}\right)-\mathrm{COOH}$ T1K: $\left.\mathrm{R}=-\mathrm{CH}\left[\left(\mathrm{CH}_{2}\right)_{2}-\mathrm{COOH}\right)\right]-\mathrm{COOH}$ T1L: $\mathrm{R}=-\mathrm{CH}\left[\left(\mathrm{CH}_{2}\right)_{2}-\mathrm{S}-\mathrm{CH}_{3}\right]-\mathrm{COOH}$ T1M: $\mathrm{R}=-\mathrm{CH}_{2}-\mathrm{CO}-\mathrm{NH}-\mathrm{CH}_{2}-\mathrm{COOH}$ T1O: $\mathrm{R}=-\mathrm{CH}\left[\left(\mathrm{CH}_{2}\right)_{2}-\mathrm{CONH}_{2}\right]-\mathrm{COOH}$
Fig. 1: general structure of the compound 3,5-disubstitutedtetrahydro-2H-1,3,5-thiadiazin-2-thiones and their derivatives, used in this study.

Glucantime (Rhône-Poulenc Rorer, Mexico) was used as the reference drug.

The strain of L. amazonensis (MHOM/77BR/LTB0016) was kindly provided by the Department of Immunology, Oswaldo Cruz Foundation, Brazil. The parasites were routinely isolated from mouse lesions and maintained as promastigotes at $26^{\circ} \mathrm{C}$ in Schneider's medium (Sigma Chem Co, St. Louis, Mo, US), containing 10\% heat-inactivated foetal bovine serum (Sigma), $200 \mathrm{U}$ penicillin/ml and 200 $\mathrm{mg}$ streptomycin/ml (Sigma). The parasites were not used after the fifth passage.

Antileishmanial activity was assessed by the method described by Caio et al. (1999). Resident macrophages were harvested from peritoneal cavities of normal BALB/ c mice in ice-cold RPMI medium (Sigma). The cells were plated at $10^{6} / \mathrm{ml}$ in Lab-Tek 16 chamber slides (Costar ${ }^{\circledR}$, Naperville, US) and incubated at $37^{\circ} \mathrm{C}$ under an atmosphere of $5 \% \mathrm{CO}_{2}$ for $2 \mathrm{~h}$. Non-adherent cells were removed by washing with pre-warmed phosphate-buffered saline (PBS). Stationary-phase L. amazonensis promastigotes were added at a 4:1 parasite/macrophage ratio, and the cultures were incubated for $4 \mathrm{~h}$, and then washed three times with pre-warmed PBS to remove free parasites. The different drugs in dimethylsulfoxide (DMSO), at a final concentration of $100 \mathrm{ng} / \mathrm{ml}$, were added, in duplicate, for $48 \mathrm{~h}$. The cultures were then fixed with absolute metha- 
nol, stained with Giemsa, and examined under light microscopy. The number of intracellular amastigotes was determined by counting the amastigotes residents on 100 macrophage per each sample, and the results were expressed as percent of reduction of the infection rate (\%IR) in comparison to that of the controls [\% IR $=100$ - (infection rate of the treated culture/infection rate of the untreated culture $\mathrm{x}$ 100)]. The infection rates were obtained by multiplying the percentage of infected macrophages by the number of amastigotes per infected macrophages (Delorenzi et al. 2001). The results were statistically analyzed by the ANOVA test, using the Statistics for Windows Program.

The effect of the compounds on amastigote-infected macrophages treated for $48 \mathrm{~h}$ is shown in Fig. 2. A noticeable inhibitory effect on the indices of the infection was seen when cultures were treated with $\mathrm{T} 1 \mathrm{~A}, \mathrm{~T} 1 \mathrm{~K}, \mathrm{~T} 1 \mathrm{~L}$ or T1O. The best result was shown by $\mathrm{T} 1 \mathrm{O}$, which caused $89 \%$ inhibition of amastigote survival. This was highly significant $(\mathrm{P}<0.01)$ in comparison to the rest of the series, and also significant in relation to glucantime $(\mathrm{P}<$ 0.01 ), which decreased the infection in $65 \%$.

The group formed by T1B, T1C, T1D, T1I, and T1M caused a reduction of the infection from 32 to $41 \%$, a result also significant $(\mathrm{P}<0.05)$ in comparison to the other compounds.

Finally, the lowest reduction in the number of parasites was obtained when cultures were treated with $\mathrm{T} 1 \mathrm{H}$, a result that differed statistically $(\mathrm{P}<0.05)$ from the rest of the series.

The evaluated compounds, except $\mathrm{T} 1 \mathrm{H}$ showed a strong activity against amastigotes at concentrations not toxic to the host cell. The toxicity was verified by direct observation of uninfected macrophage treated with thiadiazine derivatives.

When compared with other compounds tested also on intracellular amastigotes, the thiadiazine derivatives showed better results. Glucantime caused 50\% inhibition of infection at concentration of $6.6 \mu \mathrm{g} / \mathrm{ml}$, against intrac-



Fig. 2: effect of thiadiazine derivatives and Glucantime (Glu) on intracellular amastigote. Leishmania amazonensis-infected mouse peritoneal macrophages were treated with $100 \mathrm{ng} / \mathrm{ml}$ of the drugs 4 $\mathrm{h}$ after the infection and the amastigote survival was assessed $48 \mathrm{~h}$ later. Results are from three experiments in duplicate and are shown as percentages \pm standard deviations of inhibition rates in relation to untreated control. All results were highly significant $(\mathrm{P}<0.01)$ in comparison with Glucantime; except the T1A, T1K, and T1L products $(\mathrm{P}>0.05)$ ellular amastigotes of L. amazonensis (Delorenzi et al. 2001) In other hands, the amphotericin B and pentamidine at concentration of 0.26 and $4.52 \mu \mathrm{g} / \mathrm{ml}$, respectively, have caused $50 \%$ inhibition of infection against axenic amastigotes of L. amazonensis (Sereno \& Lemesre 1997).

The treatment of amastigotes of this parasite with 1 $\mu \mathrm{g} / \mathrm{ml}$ of coronaridine inhibited in a $40 \%$ the infection, whereas with 10 and $20 \mu \mathrm{g} / \mathrm{ml}$, induced inhibition of 70 and $87 \%$, respectively (Delorenzi et al. 2002).

The different activities shown by the compounds of this series provide evidence that the substitution in the 5 th position, in relation to effectiveness, influences the efficacy.

Thiadiazine derivatives showed a better activity against Leishmania parasites than the effect reported against Trypanosoma cruzi, by Ochoa et al. (1999). In that case, the more active compound was T1B, which caused a growing inhibition of $96 \%$, at a concentration of $1 \mu \mathrm{g} / \mathrm{ml}$ against trypomastigotes forms. However, in our study T1B was an irrelevant product (Ochoa et al. 1999).

The thiadiazines represent a group of compounds with significant in vitro activity against $L$. amazonensis. Our results suggest that some of them could be considered for further study as new therapeutic alternatives.

\section{ACKNOWLEDGEMENTS}

To Dr Vanessa Yardley, for their helpful advice and revision of the paper.

\section{REFERENCES}

Caio TSE, Lima MD, Kaplan MAC, Nazareth MM, RossiBergmann B 1999. Selective effect of 2',6'-dihydroxy4'methoxychalcone isolated from Piper aduncum on Leishmania amazonensis. Antimicrob Agents Chemother 43: 12341241.

Delorenzi, JC, Attias M, Gattass CR, Andrade M, Rezende C, Pinto AC, Henriques AT, Bou-Habib DC, Saraiva E 2001. Antileishmanial activity of an indole alkaloid from Peschiera australis. Antimicrob Agents Chemother 45: 1349-1354.

Delorenzi JC, Freire-de-Lima L, Gattass CR, Costa DA, He L, Kuehne ME, Saraiva E 2002. In vitro activities of Iboga alkaloid congeners coronaridine and 18-methoxycoronaridine against Leishmania amazonensis. Antimicrob Agents Chemother 46: 2111-2115.

Escobar P, Yardley V, Croft SL 2001. Activities of Hexadecylphosphocholine (Miltefosine), AmBisome, and Sodium Stibogluconate (Pentostam) against Leishmania donovani in immunodeficient scid mice. Antimicrob Agents Chemother 45: 1872-1875.

Mikus J, Harkenthal M, Steverding D, Reichiling J 2000. In vitro effect of essential oils and isolated mono- and sesquiterpenes on Leishmania major and Trypanosoma brucei. Planta Med 66: 366-368.

Ochoa C, Pérez E, Pérez R, Suárez M, Ochoa E, Rodríguez H, Gómez BA, Muelas S, Nogal JJ, Martínez RA 1999. Synthesis and antiprotozoan properties of new 3, 5-disubstituted-tetrahydro-2H-1,3,5-thiadiazine-2-tione derivatives. Drug Research 49: 764-769.

Plock A, Sokolowska-Köhler W, Presber W 2001. Application of flow cytometry and microscopical methods to characterize the effect of herbal drugs on Leishmania spp. Exp Parasitol 97: 141-153.

Sereno D, Lemesre JL 1997. Axenically cultured amastigote forms as an in vitro model for investigation of antileishmanial agents. Antimicrob Agents Chemother 41: 972-976. 